\title{
Improvement of the fatigue behaviour of cellulose/polyolefin composites using photo-chemical fibre surface modification bio-inspired by natural role models
}

\author{
Jörg Müssig • Milan Kelch • Beate Gebert • Jörg Hohe • Michael Luke • \\ Thomas Bahners
}

Received: 4 September 2019/Accepted: 13 April 2020/Published online: 29 April 2020

(C) The Author(s) 2020

\begin{abstract}
Based on the knowledge that plant structures often have graded stiffness transitions between strengthening elements and the surrounding matrix, which result in good damping behaviour and high toughness of the plant structure, the fatigue behaviour of composites made from rayon fibre and polypropylene (PP) as a matrix could be enhanced by photochemical surface modification of the regenerated cellulose fibres. The surface modification was achieved by deposition of UV-polymerized organic thin layers using pentaerythritol triacrylate (PETA) as the monomer. It has been shown earlier that the photochemical modification yields a decrease in wettability of the highly hydrophilic and water adsorbing viscose fibres and an increase in their affinity towards non-polar substances, thus promoting fibre-matrix adhesion. The presented experiments proved that the distinguished mechanical properties
\end{abstract}

J. Müssig $(\bowtie) \cdot$ M. Kelch

The Biological Materials Group, Department of Biomimetics, Faculty 5, HSB - City University of Applied Sciences Bremen, Neustadtswall 30, 28199 Bremen, Germany

e-mail: jmuessig@bionik.hs-bremen.de

B. Gebert · T. Bahners

Deutsches Textilforschungszentrum Nord-West gGmbH, Adlerstr. 1, 47798 Krefeld, Germany

J. Hohe - M. Luke

Fraunhofer-Institut für Werkstoffmechanik IWM, Wöhlerstraße 11, 79108 Freiburg, Germany of the deposited layer structure also mimic the graded transition and provide good damping and fatigue behaviour superior to either untreated rayon/PP or rayon/maleic anhydride-modified PP composites.

Keywords Bio-based composites - Fatigue $\cdot$ Photopolymerisation $\cdot$ Biomimetics $\cdot$ Regenerated cellulose

\section{Introduction}

Higher-performing composites, in particular, fibrereinforced plastics are often manufactured by using textile structures made of unidirectional infinite organic or inorganic fibres embedded in a polymer matrix. There is a growing demand for sustainable materials with an increasing interest in natural and cellulose fibres for composite application (Carus et al. 2015). The development of natural fibre market growth over the next 25 years is estimated to be up to $300 \%$ (Shah 2013). In addition to natural fibres, regenerated cellulose fibres should also benefit from this development, especially because of favourable mechanical and morphological properties of these industrially manufactured endless and more homogeneous fibres.

The mechanical properties of a fibre-reinforced composite are dependent on fibre orientation, volume content of fibres and voids and last but not least fibrematrix adhesion, which is essential for the stress 
transfer between reinforcing fibre and polymer (Borja et al. 2006; Mirza et al. 2010; Graupner et al. 2014). The poor adhesion of the highly hydrophilic regenerated cellulose fibre (e.g. viscose) to the hydrophobic matrix polymer such as polypropylene (PP) is a significant drawback that hampers extended use of these fibres (Albano et al. 1999). Several authors reported interfacial shear strengths (IFSS) between regenerated cellulose fibres and polyethylene (PE) and polypropylene (PP) in the range of 3-8.8 MPa based on fragmentation and microbond tests (Adusumalli et al. 2006, 2010; Karlsson et al. 1996; Awal et al. 2011; Müssig and Graupner 2017).

In general, dispersion forces are expected to be the major factor in the given system, so that the work of adhesion is determined by the surface energies of the materials involved and the interfacial energy. To enhance fibre-matrix adhesion in the system cellulose fibre/PP bonding agents such as maleic anhydride are frequently used to modify the PP matrix polymer (MAPP) (Felix and Gatenholm 1991; Huber and Müssig 2008; Joseph et al. 2002). Ester bonds can form between the hydroxyl groups of the cellulose fibre and the hydride carbonyl groups of MAPP thus significantly improve adhesion.

As an alternative, intense research activity is focused on the modification of natural as well as regenerated cellulose fibres to establish functional groups on the fibre surface. In addition to the enzymatic treatments, literature refers to chemical treatments in the form of a hydrophobic coating/modification of the fibre surface as well as physical surface modification (Belgacem and Gandini 2005; Bledzki et al. 2010; George et al. 2001). Other types of surface modification are silane treatments (Bledzki and Gassan 1996; Herrera-Franco and Valadez-Gonzalez 2005; Mieck et al. 1995; Park et al. 2006), treatment with isocyanates (Joly et al. 1996; Joseph et al. 1996), grafting processes (Canché-Escamilla et al. 1997; Raj et al. 1989), alkali treatments (Herrera-Franco and Valadez-Gonzalez 2005; Park et al. 2006; ValadezGonzalez et al. 1999) or C-H insertion crosslinking (CHic) processes (Abdul Hamid et al. 2019; Schuh et al. 2008; Prucker et al. 1999). Physically initiated surface modifications are also being explored, like corona and plasma treatments (Gassan and Bledzki 2000; Graupner et al. 2013; Yuan et al. 2007), vacuum UV treatments (cf. Belgacem and Gandini 2005), as well as $\gamma$ irradiation or electron radiation (Huber et al.
2010). Overall, a maximum improvement of fibrematrix adhesion by a factor of $1.5-2$ is reported from fibre surface modifications.

In a previous instalment, the authors reported on photo-chemical surface modification of viscose fibres (Bahners et al. 2018). The surface modification was achieved by deposition of UV-polymerized organic thin layers using pentaerythritol triacrylate (PETA) or allyl diallylphthalate (DAP) as monomers. The main effects of the photochemical modification refer to a decrease in wettability of the highly hydrophilic and water adsorbing viscose fibres and an increase in their affinity towards non-polar substances. An important issue in cellulose/matrix interaction is the very high amount of water adsorbed on the surface and in the pores of the cellulosic material. As could be shown by differential scanning calorimetry, this water content is evident even after more extended thermal conditioning. Due to the existence of the adsorbed water layer, one has to consider the affinity of the matrix polymer to the water-rich polar surface of the viscose fibres. Accordingly, reducing the wettability of the fibres as well as covering the water-adsorbing surface both contributed an increase in fibre-matrix adhesion.

For fibre-reinforced composites that have been optimised regarding fibre/matrix adhesion, there is often an abrupt transition in stiffness at the thin fibrematrix interphase. This sharp property transition results, for example, in reduced toughness properties of the composite. In nature, plant structures often have graded transitions between strengthening elements and the surrounding matrix. These gradients result in good damping behaviour and high toughness of the plant structure.

An excellent example of a role model in biomimetics is bamboo. Bamboo is a very resilient and versatile material. The structure of the bamboo column corresponds to a composite material because the ground tissue is traversed by strong and stiff vascular bundles, which represent a fibre reinforcement in the axial direction. Bamboo shows gradients on several levels, which give a perfect adaptation to the load: the stiffness is highest near the ground and decreases towards the tip of the column, so it is adapted to the course of the bending moment, resulting in a nearly constant tension on the surface over the entire length of the column (Amada et al. 1997). The distribution of the reinforcing vascular bundles varies over the crosssection of the column. In the outer area, where the 
highest stresses are applied, there are about eight vascular bundles per $\mathrm{mm}^{2}$, at the inner part there are only two vascular bundles per $\mathrm{mm}^{2}$ to be found (Ray et al. 2005). The Young's modulus of the vascular bundle itself is also dependent on the cross-section of the column. It increases linearly with increasing radius from the inside to the outside. Not only the stiffness but also the strength of the vascular bundles shows graded properties. The strength of the reinforcing bundles at the outside, where the highest stresses occur, shows values of about $800 \mathrm{MPa}$ and is about $300 \mathrm{MPa}$ higher than the strength of the bundles at the inside ( $\mathrm{Li}$ and Shen 2011). The cell walls of the vascular bundle itself have a stiffness gradient (Wang et al. 2011). The macro- to micro-level gradients will contribute to the good mechanical properties of bamboo, and their deeper understanding will lead to biomimetic transfers in the field of fibre composites.

Kuttner et al. (2012) had already shown that principles of the gradient structuring of plant cell walls could successfully be transferred to the modification of glass fibre surfaces by introducing a robust grafting method for polymers.

The study reported in the present article aimed to evaluate, whether the photo-chemical layer deposition would form, in a similar biomimetic manner, an interlayer architecture with graded properties to technical man-made composites based on cellulose fibre reinforced PP improving bonding as well as fatigue resistance comparable to our natural role model bamboo. The reasoning behind this concept is that the mentioned monomers PETA and DAP, due to their strong UV absorption, polymerise to explicit layers in a homo-polymerisation process. Although layer morphology varies for reasons of monomer distribution in the pore system of the textile and UV penetration into the pore system, layer thicknesses can be estimated to be of the order of several $100 \mathrm{~nm}$, hence the existence of actual layers with mechanical properties defined by their degree of cross-linking (Bahners and Gutmann 2016).

\section{Materials and methods}

Materials

Plain weave fabrics made of regenerated cellulose fibres (rayon) were used within this research (Cordenka ${ }^{\circledR}$ T1812, Cordenka GmbH \& Co. KG, Oldenburg, DE). The mass per unit area of the fabrics was $295 \mathrm{~g} / \mathrm{cm}^{2}$, the titer of weft and warp yarn $1220 \mathrm{dtex}$, threads counts per 12/cm (weft) and $10.7 / \mathrm{cm}$ (warp), respectively. As a matrix a common nucleated homopolymer polypropylene (Adstif HA840R, LyondellBasell Industries, Rotterdam, NL) was used, having a melt flow rate of $20 \mathrm{~g} / 10 \mathrm{~min}\left(230{ }^{\circ} \mathrm{C}\right.$, $2.16 \mathrm{~kg}$ ).

Photo-chemical fibre treatment

The rayon fabrics were immersed in a solution of pentaerythritol triacrylate (PETA) in isopropanol with monomer concentrations of $1 \%$ and $5 \%$, respectively. The fabrics were subsequently irradiated using a broadband $\mathrm{Hg}$ lamp with a main emission band between 200 and $300 \mathrm{~nm}$ with total emitted optical power per length of the tube of $50 \mathrm{~W} / \mathrm{cm}$ (UVA-Print, Dr Hönle, Munich, DE). It must be noted that PETA strongly absorbs over the whole emission spectrum of the broadband lamp and, accordingly, can be polymerized without any additional photo-initiator. Layer deposition on the textile substrate, therefore, results from homo-polymerization in the monomer solution and subsequent "grafting-to" (Bahners and Gutmann 2016). As layer growth is quite significant, the addition of a photo-initiator must be assumed to be detrimental to the formation of layers in the porous system of the reinforcement fabrics. Further relevant irradiation parameters were a lamp-to-sample distance of $10 \mathrm{~cm}$ and an exposure time of $5 \mathrm{~min}$. This process was completed by extraction in isopropanol to remove redundant monomers.

Test sample preparation

The composite panels were compression moulded with a small press $\left(150 \times 80 \mathrm{~mm}^{2}\right)$ with shearing edges usable for a Zwick/Roell Z020 (Zwick Roell, Ulm, DE) universal testing machine with a $20 \mathrm{kN}$ load cell. No spacers were used for composite production. 
The press plates were heated with heating cartridges. The treated and untreated rayon fabrics were first cut to size. The polypropylene matrix was sprinkled in the form of powder between the layers of fabric. The mass of the powder was adjusted to a fibre volume fraction of $50 \%$. The layered layers were pressed between PTFE films. After an extensive series of measurements, a force-controlled variation of the pressing pressure of $0.16 \mathrm{~N} / \mathrm{mm}^{2}$ for $5 \mathrm{~min}$ and subsequently of $0.78 \mathrm{~N} / \mathrm{mm}^{2}$ for $5 \mathrm{~min}$ at a constant pressing temperature of $210{ }^{\circ} \mathrm{C}$ turned out to be the ideal process variant. For the reference samples with an adhesion promoter, the pressing temperature was increased to $220{ }^{\circ} \mathrm{C}$ due to the changed melting behaviour of the used 2\% MA coupled polypropylene. Composite plates were produced with a thickness of about $2 \mathrm{~mm}$ (6 fabric layers, for quasi-static tensile and fatigue tests) and about $4 \mathrm{~mm}$ (12 fabric layers, for fibre content investigation). The weft threads ran parallel to the tensile direction in the mechanical analyses.

The composite structures were consolidated by cold pressing between aluminium plates, which resulted in dimensions of the plate of $80 \times 80 \times 4 \mathrm{~mm}^{3}$.

Fibre volume content

Samples were taken from the $4 \mathrm{~mm}$ thick plates with a width of $25 \mathrm{~mm}$ and a length of $65 \mathrm{~mm}$ to check the fibre volume content of the composites. One plate made with untreated rayon fabric and two plates with different treatment configurations of rayon fabric were selected for the measurements. Three samples were taken from each plate. The sample volume was determined by measuring the width, thickness and length at three positions on each specimen with a digital calliper gauge (500-171-20, Mitutoyo, Neuss, $\mathrm{DE})$. The mass of the fibres in the composite material was calculated using the known number of fabric layers, the grammage of the fabric of $295 \mathrm{~g} / \mathrm{m}^{2}$ and the density of the fibres of $1.5 \mathrm{~g} / \mathrm{cm}^{3}$ in relation to the measured total mass (measured with a fine-scale Type 440 35N, Kern \& Sohn GmbH, Balingen, DE). The determined fibre volume content was $65 \%$ (standard deviation: $2 \%, \mathrm{n}=9$ ) averaged over all samples. There was no clear difference between plates with untreated or treated fabrics. Since some of the polymer was pressed out at the edge of the mould during the compression moulding of the plates, the fibre volume content obtained was about $15 \%$ higher than the desired one.

Sample conditioning

Before mechanical testing, the samples were stored in a standard plastic climate with $23{ }^{\circ} \mathrm{C}$ and $50 \%$ rel. humidity for at least $18 \mathrm{~h}$.

Composite tensile strength

The fatigue test specimens were cut to a total length of $100 \mathrm{~mm}$ and a width of $10 \mathrm{~mm}$ from $2 \mathrm{~mm}$ thick plates using a jigsaw (MBS 240/E, PROXXON S.A., Wecker, LU). In the clamping area, $1 \mathrm{~mm}$ thick glass fibre-reinforced cap strips (GRP) were glued on the specimens with a cyanoacrylate adhesive (Art. No.: 46130, UHU GmbH \& Co. KG, Bühl, DE) (Fig. 1).

The sample cross-section was determined by measuring the width and thickness at three positions of the specimen (upper, middle and lower part) with a digital calliper gauge (500-171-20, Mitutoyo, Neuss, DE). After conditioning in standard climate $\left(23{ }^{\circ} \mathrm{C}, 50 \%\right.$ relative humidity), the tensile tests were carried out with a universal testing device (Z020 with $20 \mathrm{kN}$ load cell, pneumatic clamps type 8497.00.00, Zwick Roell, Ulm, DE). A clamping length of $25 \mathrm{~mm}$, a loading speed of $1 \mathrm{~mm} / \mathrm{min}$, a pre-load of $5 \mathrm{~N}$ and a clamping pressure of 2.5 bar were used. The tensile strain was measured using the data of the traverse path.

\section{Fatigue testing}

From composite plates $2 \mathrm{~mm}$ thick (6 fabric layers), strip-shaped tensile specimens with a width of $10 \mathrm{~mm}$ and a length of $77 \mathrm{~mm}$ were cut. The specimens were tested without cap strips to avoid problems due to fatigue of the cap strips themselves and especially their adhesive bond with the specimen itself in the vicinity of the stress concentration at the cap-strip ends. Fatigue degradation in this range might cause a general softening of the specimen-cap-strip assembly which is not related to fatigue degradation of the specimens gauge section. Furthermore, since the material under consideration is comparatively soft (compared, e.g. to standard carbon fibre epoxy composites) and since the axial loads do not result in a considerable thinning due to the Poisson effect, cap strips serving as spring elements for compensation of 

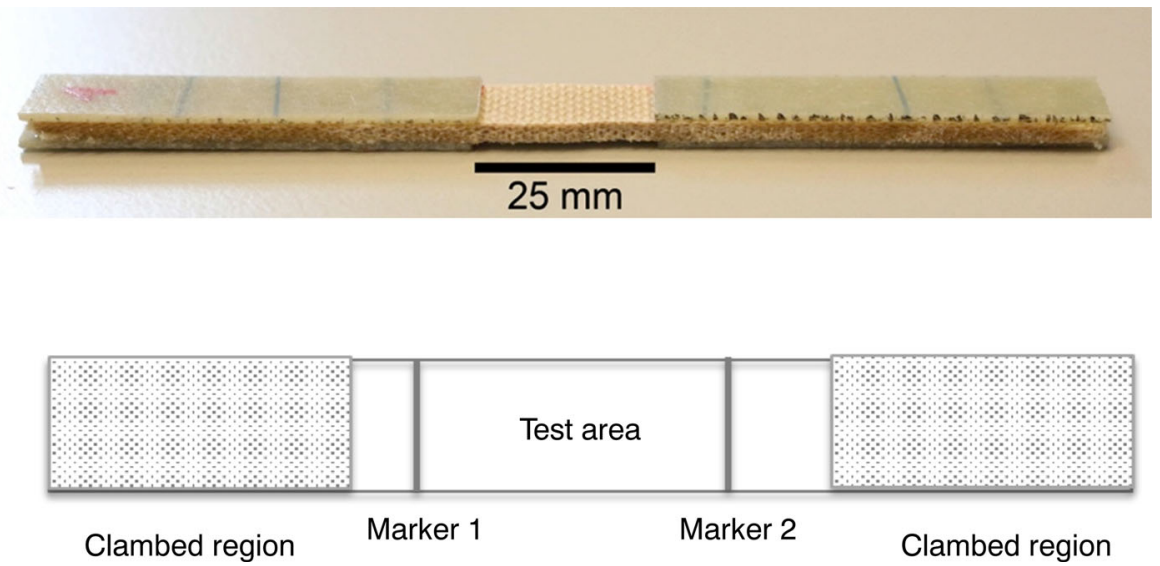

Fig. 1 Test specimen with cap strips for the quasi-static tensile and cyclic fatigue tests (width of $10 \mathrm{~mm}$ and a length of $77 \mathrm{~mm}$ ). Since no problems regarding the clamping of the specimens in the test fixture were encountered, all specimens were tested without cap strips

the Poisson thickness loss were considered to be unnecessary.

The specimens were tested using parallel mechanical fixtures in an MTS testing machine (858 Mini Bionix II, MTS Systems Corporation, Eden Prairie, USA, Fig. 2). The cyclic test was carried out under tensile stress $(\mathrm{R}=0.1)$ under force control at a given upper and lower force. The load horizons were determined according to the so-called "bead-string method" during the respective test series based on the already existing quasi-static strengths (see Fig. 4 and Table 2) such that the time-stable range of $10^{3}-10^{6}$ cycles was uniformly covered. Experiments that reached a total cycle number of 1 million cycles were considered as run-outs. The fatigue tests were performed uniformly at a specified test frequency of $10 \mathrm{~Hz}$. During the tests, the temperature of the specimens was controlled at selected instants. No inherent heating was observed in any test. Each experiment was carried out until the specimen broke or until one million load cycles were reached.

\section{SEM}

Scanning electron microscopy (SEM) was employed for qualitative fracture analysis using a JSM-6510 instrument (Joel GmbH, Freising, DE). Samples were previously sputtered with gold in argon atmosphere throughout $80 \mathrm{~s}$ at $65 \mathrm{~mA}$ (SputterCoater SCD 005, BAL-TEC, LIE). Micrographs were taken in SE mode with 5 and $10 \mathrm{kV}$ acceleration voltage.

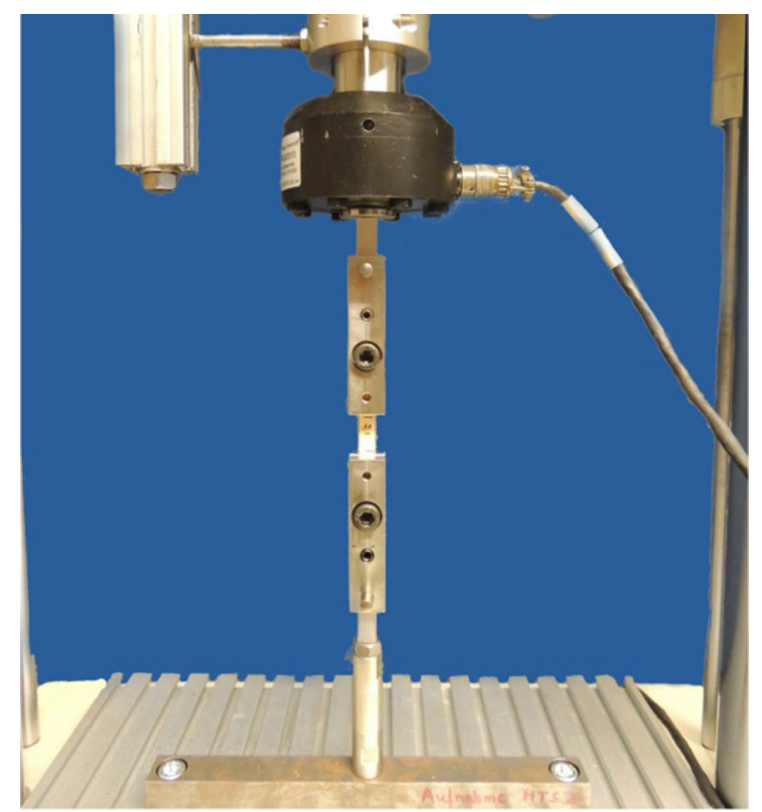

Fig. 2 Experimental setup for the fatigue strength test

\section{Statistics}

The results obtained in the investigations were initially checked for a normal distribution. For a small sample size under 6, the rapid test according to David et al. was used (Microsoft Excel version 2010, Microsoft Cooperation, Redmond, USA) with a significance level of $\alpha=0.01$. For normally distributed samples, the mean with standard deviation is given in the results part. The distribution-independent Wilcoxon ranksum test was performed in $\mathrm{R}$ (version 3.3.2, $\mathrm{R}$ 
Foundation for Statistical Computing) to analyse significant differences. The p-value adjustment method, according to Holm, was used. For a $p$ value of less than 0.05 , it is assumed that there is a significant difference between the data.

\section{Results and discussion}

Composite processing and characterization

From the mechanical investigations at fibre and interphase level (compare Bahners et al. 2018) it becomes clear that a higher fibre-matrix adhesion can be achieved by the deposition of thin PETA layers on the regenerated cellulose fibres. In our previous study (Bahners et al. 2018), we already observed that at higher monomer concentrations, occlusion of the fibre interstices by cross-linked PETA occur. Based on the preliminary investigations, fabrics were selected for the manufacture of the composites, which were treated with a $1 \%$ and 5\% PETA solution (Table 1). As reference composite plates manufactured of untreated fibres in the pure PP matrix, as well as MAPP coupled composites, were used.

A crucial question in composite production was whether the impregnation of semi-finished textiles during compression moulding is influenced by the deposition of the thin layers on and between the fibres. Figure 3 clearly shows that the deposition of thin PETA films does not affect the impregnation of weft and warp yarns. Only in very small areas (dark spots) in the interior of the yarn structure gaps between individual fibres are not filled with polymer. However, this was also observed in the composites made from untreated fabrics.
Tensile testing

The values of the quasi-static tensile strengths are shown in Fig. 4. The significantly highest tensile strengths were achieved with composites made with $1 \%$ PETA solution treated fabrics. For the 5\% PETA variant as well as for the variant with MA coupling agent, no significant difference was found in comparison to the untreated reference samples.

When considering the fracture surfaces, it was possible to observe the withdrawal of entire yarn structures in all variants. Within the yarns, there is a difference in the fracture pattern between the series of measurements (Fig. 5). While the untreated fibres protrude very far from the fracture surfaces (Fig. 5), the pull-out lengths are smaller in the 1\% PETA variant (Fig. 5). A much smoother fracture surface can be observed within the weft threads of the 5\% PETA variant (Fig. 5). The outer fibres in the sample with a conventional coupling agent (MA) break off flush with the matrix. This phenomenon was also dominant in the fibre pull-out tests (compare Bahners et al. 2018). These observations reflect a tendency, which could not be confirmed for every region of the fractured surfaces. However, the trend observed at the fracture surfaces suggests an increasingly brittle behaviour along with the illustrated series of measurements.

The stress-strain curves from the tensile tests can be found in Fig. 6 taken from our previous research (Bahners et al. 2018).

All samples have typical curves for individual rayon fibres. The slope of the curves in the linear elastic range is higher for the thin-films and the MAmodified samples than for the untreated composites, which is reflected in Young's modulus values, which are significantly higher for the modified samples than

Table 1 Selection of semi-finished textile products and matrix polymers for the production of composite panels

\begin{tabular}{lllll}
\hline Sample & Untreated & $1 \%$ PETA & 5\% PETA & MAPP \\
\hline Textile & Rayon fabric $0^{\circ} / 90^{\circ}$ & Rayon fabric $0 \% / 90^{\circ}$ & Rayon fabric $0^{\circ} / 90^{\circ}$ & Rayon fabric $0^{\circ} / 90^{\circ}$ \\
Monomer concentration & - & $1 \%$ PETA & $5 \%$ PETA & - \\
Radiation treatment & - & Broadband 5 min & Broadband 5 min & - \\
Matrix polymer & Adstif HA840R & Adstif HA840R & Adstif HA840R & Adstif HA840R \\
Coupling agent & - & - & - & $2 \%$ MA \\
\hline
\end{tabular}

For the fabrics with a photochemically crosslinked thin layer, the monomer concentration used and the radiation source with radiation duration are shown. MA = maleic anhydride 

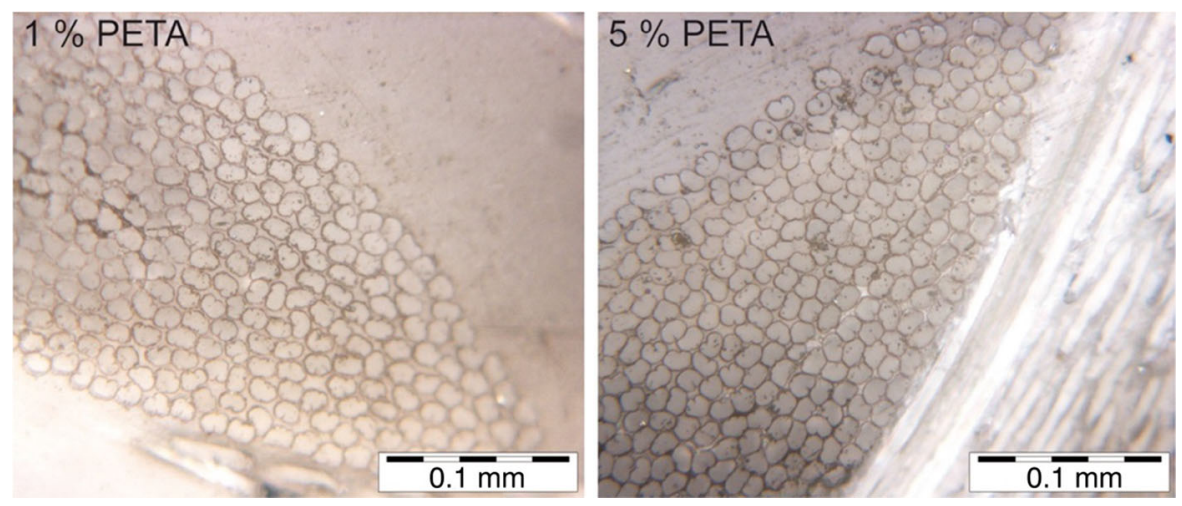

Fig. 3 Micrographs of a section through composite plates of regenerated cellulose fibres in a polypropylene matrix. The cross-section through a yarn structure can be seen in each case

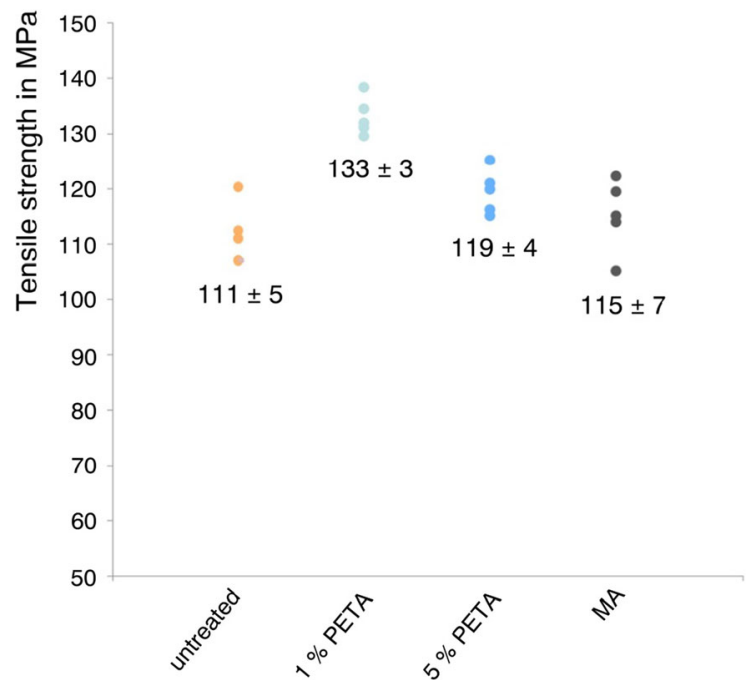

Fig. 4 Quasi-static tensile strength values. For all samples the data are statistically normal distributed, the measured values for all specimens are shown, and the mean value with standard deviation is given (sample size was 5)

for the untreated samples (compare Bahners et al. 2018). Within the modified variants, no significant differences can be found. The higher tensile strength of the $1 \%$ PETA variant results from a steeper increase in mid-curve stresses, indicating a better and more effective force transfer from the matrix to the fibre, and thus better utilisation of fibre properties.

Fatigue testing

The fatigue behaviour of the samples was evaluated in a cyclic test carried out under tensile stress with force control at a given upper and lower force at a specified

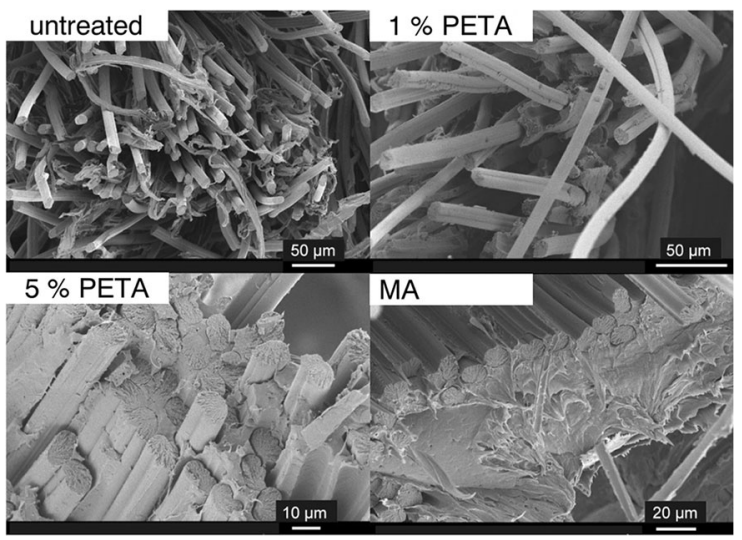

Fig. 5 Representative fracture surfaces from the tensile tests

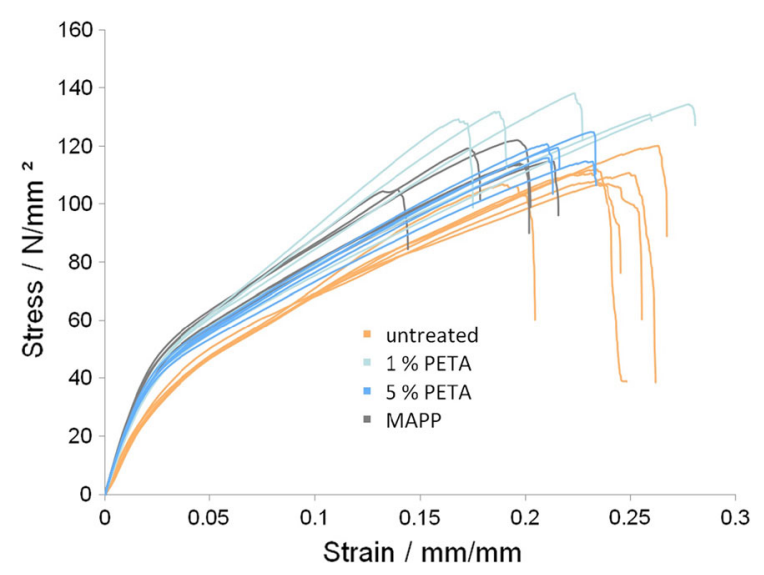

Fig. 6 Stress-strain behaviour of composite samples made of (modified) viscose fibres and PP matrix and the viscose fibre/ MAPP system (Bahners et al. 2018) 
test frequency of $10 \mathrm{~Hz}$. Each experiment was carried out until the specimen broke or until one million load cycles were reached.

Considerable qualitative differences were found in the fracture patterns, where samples failed during the cyclic test. The fracture patterns of the untreated samples, of the MA treated samples, and of the samples treated with $1 \%$ and 5\% PETA are shown in Figs. 7, 8, 9 and 10, respectively. In all cases, fractures start from the edge of the clamps (compare Fig. 1). It can be observed that the fibre pull-out is high in the case of untreated and low in the case of the MA treated samples. The fibre and yarn pull-out exhibited by the photo-chemically modified samples was found to be smaller than the untreated samples, but higher than for the MA modified samples.

In some cases of untreated samples and samples modified with $1 \%$ PETA, delamination of the single outer layers occurs with partial separation and breakage of the delaminated middle area. No delamination was observed in case of the MA modified samples and all samples modified with 5\% PETA.

A quantitative assessment of the samples' fatigue behaviour is given in the form of the $\mathrm{S}-\mathrm{N}$ diagram, which relates the difference between the applied upper and lower tensile stress $\Delta \sigma$ (load or stress range) to the number of cycles $\mathrm{N}_{\mathrm{f}}$, at which the fracture occurred. In a logarithmic representation of the data, a linear behaviour is expected, which can be extrapolated to $\mathrm{N}_{\mathrm{f}}=10^{6}$ cycles and the related fatigue strength of the samples.

The relevant S-N diagrams of the untreated samples, of the MA treated samples and of the samples treated with 1\%, and 5\% PETA are shown in Figs. 11, 12, 13 and 14, respectively.

Table 2 summarises the cyclic properties of all four types of composites tested. For the evaluation of the cyclic strength, in particular, $\Delta \sigma\left(\mathrm{N}_{\mathrm{f}}=10^{6}\right)$ and the slope $(-\mathrm{d} \log \mathrm{N} / \mathrm{d} \log \Delta \sigma)$ of the $\mathrm{S}-\mathrm{N}$ curve is of importance. $\Delta \sigma\left(\mathrm{N}_{\mathrm{f}}=10^{6}\right)$ is rated as the related fatigue strength. Indicated are in Table 2 the median as well as the 5\% and $95 \%$ quantiles. Also informative is the quasi-static strength $\mathrm{R}_{\mathrm{m}}{ }^{\text {stat }}$, as well as the limit value $\Delta \sigma\left(\mathrm{N}_{\mathrm{f}}=1\right)$ of the $\mathrm{S}-\mathrm{N}$ curve (extrapolated for a single cycle).

All S-N curves feature comparatively low coefficients of proportionality in the range between 22.7 and 31.0 , which can be regarded as typical for fibrereinforced composite materials. The sample with untreated fabrics and the variant with $1 \%$ PETA solution of cross-linked thin films show the lowest slope of the S-N curves. As a result, the lowest strength drop is observed with a high number of load cycles compared to the quasi-static strength.

The value $\Delta \sigma\left(\mathrm{N}=10^{6}\right)$ representing the related fatigue strength follows the observed trend in quasi-

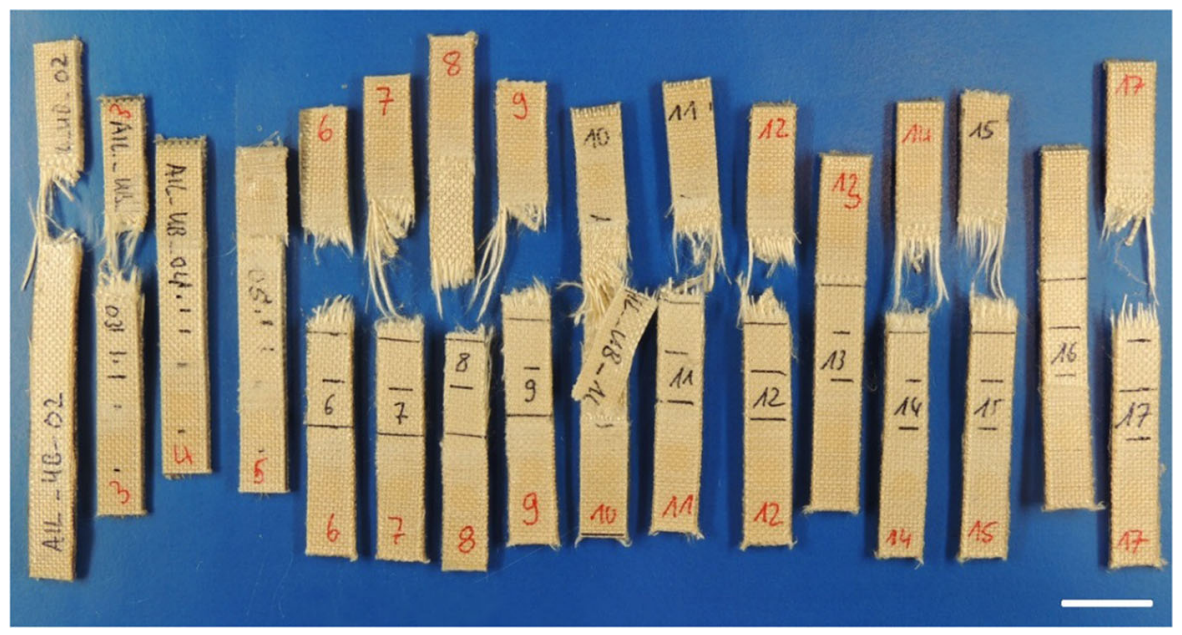

Fig. 7 Fracture patterns of the samples (untreated) after fatigue testing. It turns out that all the samples except for the run-outs final fracture initiated at the edge of the clamp. A fracture pattern with a clear yarn and fibre pull-out is visible. In some cases, (for example sample AIL_UB_10) delamination of the single outer layers occurs with partial separation and breakage of the delaminated middle area 


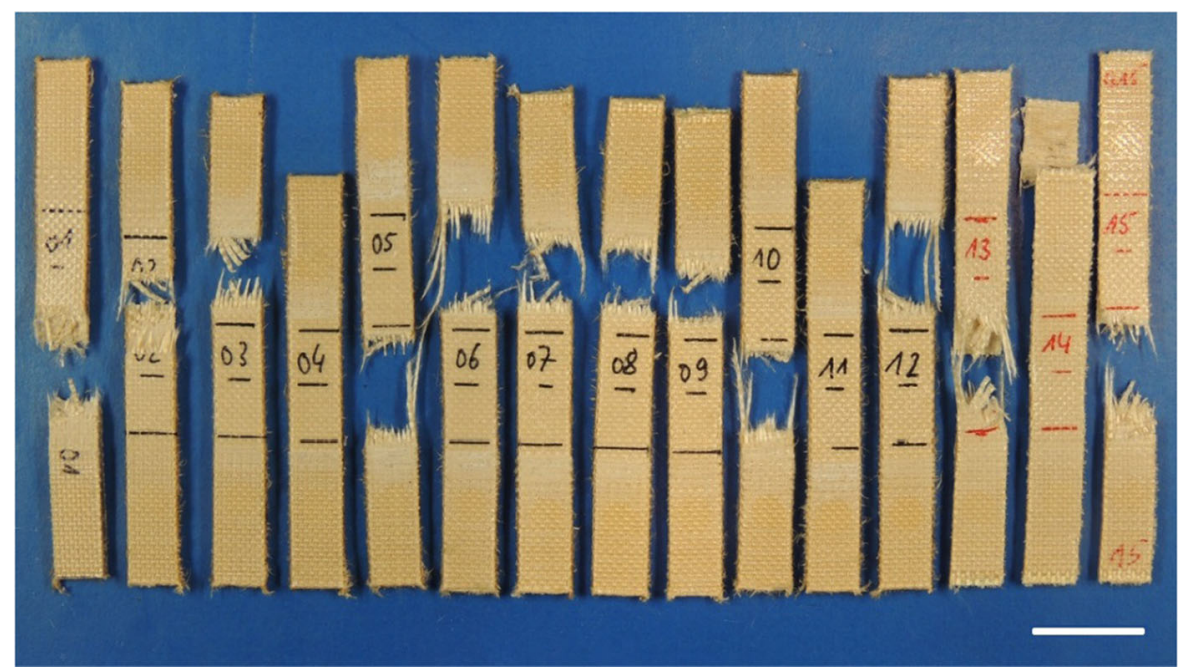

Fig. 8 Fracture patterns of the $1 \%$ PETA treated specimens after fatigue testing. The specimens except for the run-outs mostly fractured from the edge of the clamp. In contrast to the untreated specimens (compare Fig. 7), the fracture behaviour shows a significantly lower, but in comparison to the MA treated specimens (compare Fig. 8) longer fibre and yarn pull-outs and less fragmented cracks. In some cases (notably samples AIL_1\% PETA_13 and AIL_1\% PETA_14) the failure is accompanied by partial delamination of individual layers

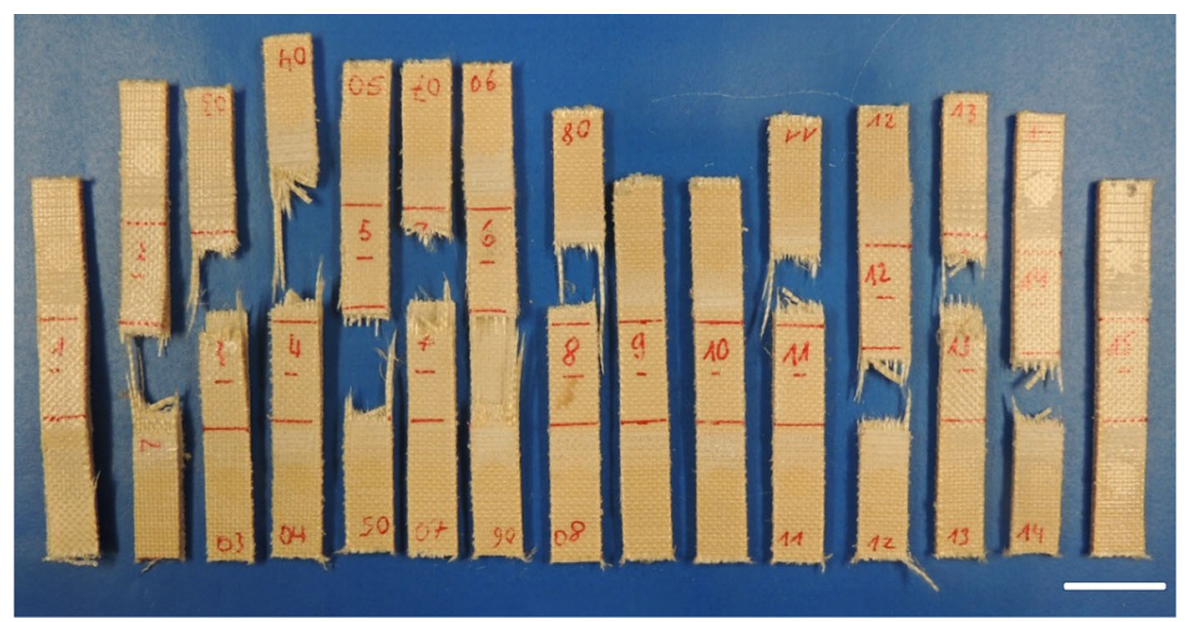

Fig. 9 Fracture patterns of the 5\% PETA treated specimens after fatigue testing. The specimens except for the run-outs mostly fractured from the edge of the clamp and show a similar fracture behaviour as the $1 \%$ PETA treated specimens. However, significant delamination is not observed static strength values (compare Fig. 4) concerning the influence of treatment. Thus, for the untreated variant and the variant with MA as coupling agent, cyclic strength values result in a similar height. The photochemically cross-linked thin films achieve a significantly higher fatigue strength of the composites at a monomer concentration of $1 \%$ PETA. For the variant with 5\% PETA, the fatigue strength is somewhat lower but still higher than the reference samples. Here, one has to note that the poly-PETA layer is formed by homo-polymerisation and a subsequent "grafting-to" deposition. The slightly reduced radical generation in 


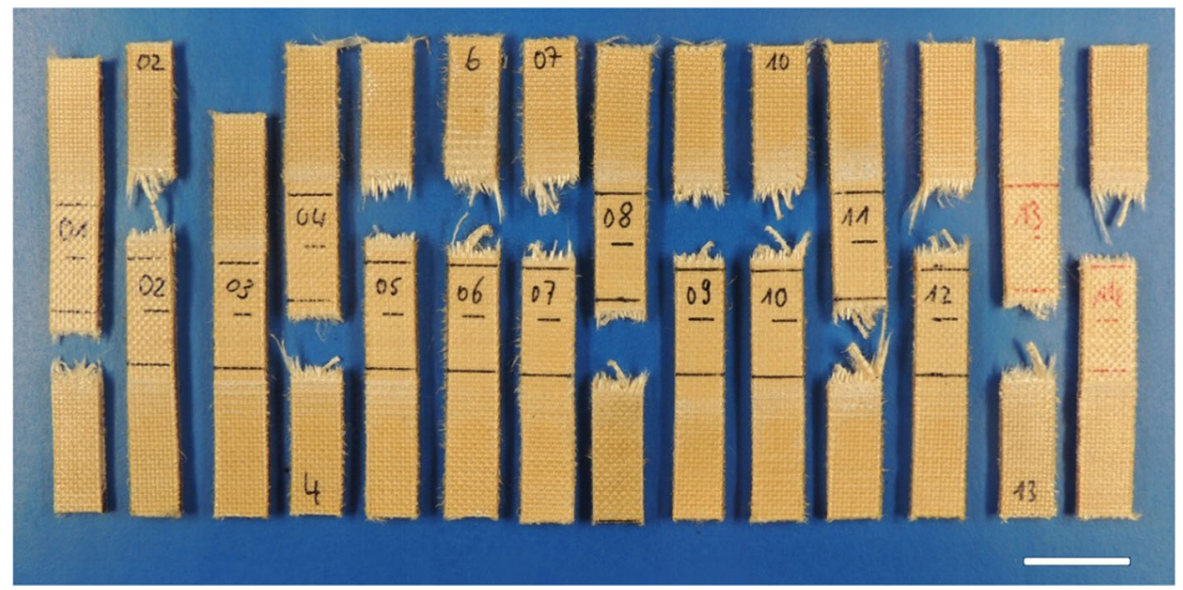

Fig. 10 Fracture patterns of the MA treated samples after fatigue testing. All samples except for the run-outs fractured from the edge of the clamp. In contrast to the untreated

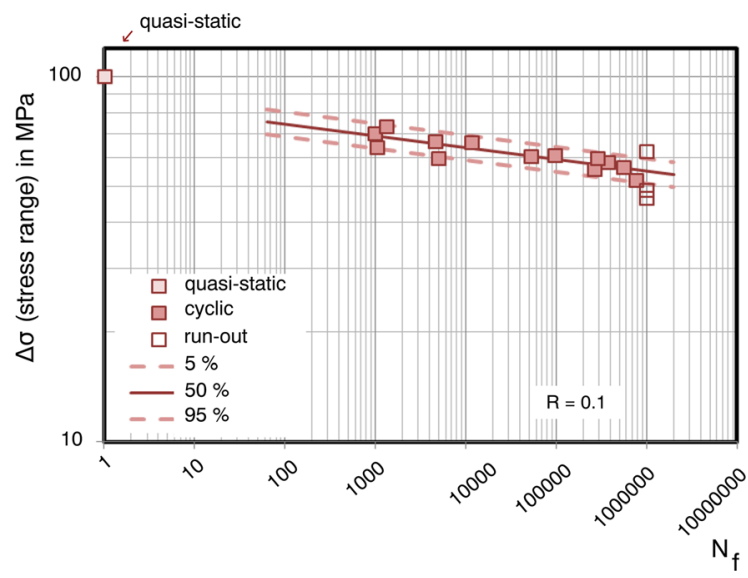

Fig. 11 S-N diagram of the composite with untreated fabrics

the $1 \%$ solution in combination with an improved penetration of monomer solution and radiation into the pore system of the reinforcement fabrics may thus be assumed to be the reason for more complete coverage of available fibre surfaces and the favourable mechanical properties. It is noticeable that the specimens with MA treatment have a much larger scatter in the fatigue test results (compare Fig. 14). It can be shown that the deposition of thin PETA films not only has a positive effect on the quasi-static tensile strength but also on the fatigue strength. specimens (compare Fig. 7), the fracture behaviour shows a significantly lower yarn as well as fibre pull-out separation and less fragmented cracks. Notable delaminations are not observed

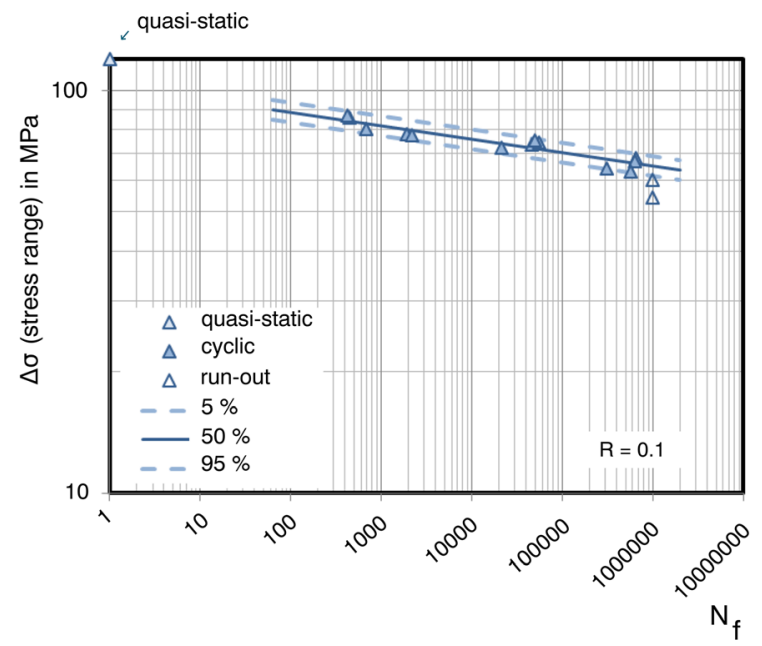

Fig. 12 S-N diagram of the composite with 1\% PETA treated fabrics

\section{Summary and outlook}

The fatigue performance of composites made from fabrics based on regenerated cellulose fibres and polypropylene as a matrix was improved by photochemical surface modification of the fibres. The surface modification was achieved by deposition of UV-polymerized organic thin layers using pentaerythritol triacrylate (PETA) as the monomer. 


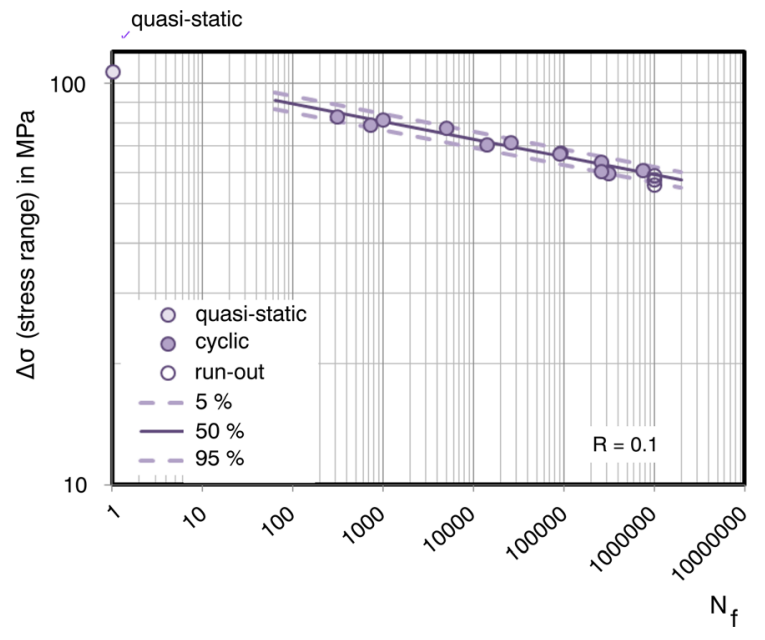

Fig. 13 S-N diagram of the composite with 5\% PETA treated fabrics

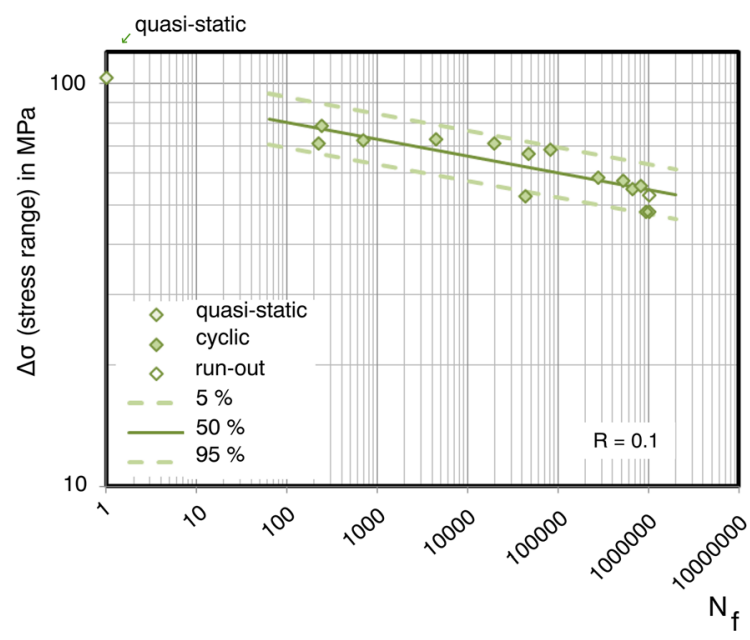

The photo-chemically cross-linked thin films achieve a significantly higher fatigue strength at a monomer concentration of $1 \%$ PETA. For the variant with 5\% PETA, the fatigue strength was somewhat lower but still higher than the values of the reference samples. Critical to the evaluation of the investigated photochemical modification was the following aspect: the MA treated specimens exhibited a significantly larger scatter in the cyclic results. It could thus be shown that the photochemical deposition of hydrophobic thin films not only has a positive effect on the quasi-static tensile strength but also on the fatigue strength under cyclic load.

In nature, one can find plant structures such as bamboo that are exposed to high mechanical and cyclic loads and require good damping properties. The high load capacity of these structures is known to be due to gradual stiffness transitions between strengthening elements and the surrounding matrix, which prevent failure of the boundary layer and lead to high "fatigue strength" (Li and Shen 2011; Wang et al. 2011).

Our work shows that the development of a biomimetic gradation of the interphase by deposition of photo-chemically generated hydrophobic thin films on fibre surfaces can lead to optimised composite fatigue properties.

Fig. 14 S-N diagram of the composite with MA treated fabrics

Table 2 Material properties determined in fatigue tests

\begin{tabular}{|c|c|c|c|c|c|c|c|c|}
\hline \multirow[t]{2}{*}{ Sample } & \multirow[t]{2}{*}{$\mathrm{R}_{\mathrm{m}}^{\text {stat }}$ in $\mathrm{MPa}$} & \multicolumn{3}{|c|}{$\Delta \sigma(\mathrm{N}=1)$ in $\mathrm{MPa}$} & \multicolumn{3}{|c|}{$\Delta \sigma\left(\mathrm{N}=10^{6}\right)$ in $\mathrm{MPa}$} & \multirow[t]{2}{*}{$-\mathrm{d} \log \mathrm{N} / \mathrm{d} \log \Delta \sigma$} \\
\hline & & $5 \%$ & $50 \%$ & $95 \%$ & $5 \%$ & $50 \%$ & $95 \%$ & \\
\hline Untreated & 111.3 & 79.7 & 86.2 & 93.2 & 51.0 & 55.2 & 59.7 & 31.0 \\
\hline $1 \%$ PETA & 132.9 & 97.5 & 103.3 & 109.4 & 61.3 & 64.9 & 68.7 & 29.8 \\
\hline $5 \%$ PETA & 119.2 & 104.1 & 109.0 & 114.1 & 56.6 & 59.2 & 62.0 & 22.7 \\
\hline MAPP & 115.0 & 84.1 & 97.2 & 112.4 & 47.4 & 54.7 & 63.3 & 24.1 \\
\hline
\end{tabular}

$\mathrm{R}_{\mathrm{m}}{ }^{\text {stat }}=$ quasi-static strength; $\Delta \sigma\left(\mathrm{N}_{\mathrm{f}}=1\right)=$ limit of the $\mathrm{S}-\mathrm{N}$ curve for a single cycle shown with median (50\%) and the $5 \%$ and $95 \%$ quantiles; $\Delta \sigma\left(\mathrm{N}_{\mathrm{f}}=10^{6}\right)$ as related fatigue with median $(50 \%)$ and the $5 \%$ and $95 \%$ quantiles; $-\mathrm{d} \log \mathrm{N} / \mathrm{d} \log \Delta \sigma=$ slope of the S$\mathrm{N}$ curve. Higher values are an indicator for a lower slope 
Acknowledgments Open Access funding provided by Projekt DEAL. The research Project IGF-Nr. 18059N of Forschungskuratorium Textil e. V. was funded by the Bundesministerium für Wirtschaft und Energie in the framework of the program Industrielle Gemeinschaftsforschung (IGF) based on a decision by Deutscher Bundestag. The authors are indebted to Mr Andy Dentel and $\mathrm{Mr}$ Stefan Seidel, BOND Laminates, Brilon, Germany for their great support, for many fruitful discussions and the opportunity to use their equipment for cell phone shell manufacturing. The kind help of Cordenka GmbH \& Co. KG (Obernburg, Germany) and Mr Rudolf Einsiedel by providing rayon fabrics for the experiments are greatly acknowledged.

Open Access This article is licensed under a Creative Commons Attribution 4.0 International License, which permits use, sharing, adaptation, distribution and reproduction in any medium or format, as long as you give appropriate credit to the original author(s) and the source, provide a link to the Creative Commons licence, and indicate if changes were made. The images or other third party material in this article are included in the article's Creative Commons licence, unless indicated otherwise in a credit line to the material. If material is not included in the article's Creative Commons licence and your intended use is not permitted by statutory regulation or exceeds the permitted use, you will need to obtain permission directly from the copyright holder. To view a copy of this licence, visit http://creativecommons.org/licenses/by/4.0/.

\section{References}

Abdul Hamid ZM, Florea M, Fliegener S, Schober M, Hohe J, Rühe J (2019) Chemical modification of fiber-matrix interfaces of glass fiber reinforced thermoplastics and methods for interface characterization. Adv Eng Mater 21:1800590

Adusumalli RB, Reifferscheid M, Weber HK, Roeder T, Sixta H, Gindl W (2006) Mechanical properties of regenerated cellulose fibers for composites. Macromol Symp 244:119-125

Adusumalli RB, Weber HK, Roeder T, Sixta H, Gindl W (2010) Evaluation of experimental parameters in the microbond test with regard to lyocell fibers. J Reinf Plast Compos 29:2356-2367

Albano C, González J, Ichazo M, Kaiser D (1999) Thermal stability of blends of polyolefins and sisal fiber. Polym Degrad Stab 66:179-190

Amada S, Ichikawa Y, Munekata T, Nagase Y, Shimizu H (1997) Fiber texture and mechanical graded structure of bamboo. Composites B 28:13-20

Awal A, Cescutti G, Ghosh SB, Müssig J (2011) Interfacial studies of natural fibre/polypropylene composites using single fibre fragmentation test (SFFT). Composites A 42:50-56. https://doi.org/10.1016/j.compositesa.2010.10. 007

Bahners T, Gutmann JS (2016) Using bulk properties of photopolymerized thin layers for fiber modification. Surf Innov 4:14-22
Bahners T, Kelch M, Gebert B, Osorio Barajas XL, Schmidt TC, Gutmann JS, Müssig J (2018) Improvement of fibre-matrix adhesion in cellulose/polyolefin composite materials by means of photo-chemical fibre surface modification. Cellulose 25(4):2451-2471. https://doi.org/10.1007/s10570$018-1724-4$

Belgacem M, Gandini A (2005) The surface modification of cellulose fibers for use as reinforcing elements in composite materials. Compos Interf 12:41-75

Bledzki AK, Mamun AA, Jaszkiewicz A, Erdmann K (2010) Polypropylene composites with enzyme modified abaca fiber. Compos Sci Technol 70:854-860

Bledzki AK, Gassan J (1996) Einfluss von Haftvermittlern auf das Feuchteverhalten naturfaserverstärkter Kunststoffe. Angew Makromol Chem 236:129-138

Borja Y, Rieß G, Lederer K (2006) Synthesis and characterization of polypropylene reinforced with cellulose I and II fibers. J Appl Polym Sci 101:364-369

Canché-Escamilla G, Rodríguez-Trujillo G, Herrera-Franco PJ, Mendizábal E, Puig JE (1997) Preparation and characterization of henequen cellulose grafted with methyl methacrylate and its application in composites. J Appl Polym Sci 66:339-346

Carus M, Eder A, Dammer L, Essel R, Barth M, Korte H (2015) Wood-plastic composites (WPC) and natural-fibre composites (NFC): European and Global Markets 2012 and future trends in automotive and construction. nova-Institut $\mathrm{GmbH}$, Hürth

Felix J, Gatenholm P (1991) The nature of adhesion in composites of modified cellulose fibers and polypropylene. J Appl Polym Sci 42:609-620

Gassan J, Bledzki A (2000) Possibilities to improve the properties of natural fiber reinforced plastics by fiber modification-jute polypropylene composites. Appl Compos Mater 7:373-385

George J, Sreekala M, Thomas S (2001) A review on interface modification and characterization of natural fiber reinforced plastic composites. Polym Eng Sci 41:1471-1485

Graupner N, Albrecht K, Hegemann D, Müssig J (2013) Plasma modification of man-made cellulose fibers (Lyocell) for improved fiber/matrix adhesion in poly (lactic acid) composites. J Appl Polym Sci 128:4378-4386

Graupner N, Rößler J, Ziegmann G, Müssig J (2014) Fibre/matrix adhesion of cellulose fibres in PLA, PP and MAPP: a critical review of pull-out test, microbond test and single fibre fragmentation test results. Composites A 63:133-148. https://doi.org/10.1016/j.compositesa.2014. 04.011

Herrera-Franco PJ, Valadez-Gonzalez A (2005) A study of the mechanical properties of short natural-fiber reinforced composites. Composites B 36:597-608

Huber T, Müssig J (2008) Fibre matrix adhesion of natural fibres cotton, flax and hemp in polymeric matrices analyzed with the single fibre fragmentation test. Compos Interfaces 15:335-349

Huber T, Biedermann U, Müssig J (2010) Enhancing the fibre matrix adhesion of natural fibre reinforced polypropylene by electron radiation analyzed with the single fibre fragmentation test. Compos Interfaces 17:371-381. https://doi. org/10.1163/092764410X495270 
Joly C, Gauthier R, Escoubes M (1996) Partial masking of cellulosic fiber hydrophilicity for composite applications. Water sorption by chemically modified fibers. J Appl Polym Sci 61:57-69

Joseph K, Varghese S, Kalaprasad G, Thomas S, Prasannakumari L, Koshy P, Pavithran C (1996) Influence of interfacial adhesion on the mechanical properties and fracture behaviour of short sisal fiber reinforced polymer composites. Eur Polym J 32:1243-1250

Joseph P, Rabello M, Mattoso L, Jospeh K, Thomas S (2002) Environmental effects on the degradation behaviour of sisal fiber reinforced polypropylene composites. Compos Sci Technol 62:1357-1372

Karlsson JO, Blachot JF, Peguy A, Gatenholm P (1996) Improvement of adhesion between polyethylene and regenerated cellulose fibers by surface fibrillation. Polym Compos 17:300-304

Kuttner C, Tebbe M, Schlaad H, Burgert I, Fery A (2012) Photochemical synthesis of polymeric fiber coatings and their embedding in matrix material: morphology and nanomechanical properties at the fiber-matrix interface. ACS Appl Mater Interfaces 4(7):3484-3492. https://doi. org/10.1021/am300576c

Li H, Shen S (2011) Experimental investigation on mechanical behavior of Moso Bamboo vascular bundles. Key Eng Mater 462-463:744-749

Mieck KP, Nechwatal A, Knobelsdorf C (1995) Faser-MatrixHaftung in Kunststoffverbunden aus thermoplastischer Matrix und Flachs, 2: Die Anwendung von funktionalisiertem Polypropylen. Angew Makromol Chem 225:37-49

Mirza FA, Rasel SM, Kim MS, Afsar AM, Kim BS, Song JI (2010) Lyocell fiber reinforced polypropylene composites: effect of matrix modification. Adv Mater Res 123-125:1159-1162

Müssig J, Graupner N (2017) Characterisation of fibre/matrix adhesion in biobased fibre-reinforced thermoplastic composites. In: Mittal KL, Bahners T (eds) Textile finishing: recent developments and future trends. Scrivener Publishing, Beverly, pp 485-556

Park JM, Quang ST, Hwang BS, DeVries KL (2006) Interfacial evaluation of modified jute and hemp fibers/polypropylene
(PP)-maleic anhydride polypropylene copolymers (PPMAPP) composites using micromechanical technique and nondestructive acoustic emission. Compos Sci Technol 66:2686-2699

Prucker O, Naumann CA, Rühe J, Knoll W, Frank CW (1999) Photochemical attachment of polymer films to solid surfaces via monolayers of benzophenone derivatives. J Am Chem Soc 121:8766-8770

Raj RG, Kokta BV, Maldas D, Daneault C (1989) Use of wood fibers in thermoplastics. VII. The effect of coupling agents in polyethylene-wood fiber composites. J Appl Polym Sci 37:1089-1103

Ray A, Mondal S, Das S, Ramachandrarao P (2005) Bamboo: a functionally graded composite-correlation between microstructure and mechanical strength. J Mater Sci 40:5249-5253

Schuh K, Prucker O, Rühe J (2008) Surface attached polymer networks through thermally induced cross-linking of sulfonyl azide group containing polymers. Macromolecules 41:9284-9289

Shah DU (2013) Developing plant fibre composites for structural applications by optimising composite parameters: a critical review. J Mater Sci 48(18):6083-6107

Valadez-Gonzalez A, Cervantes-Uc JM, Olayo R, HerreraFranco PJ (1999) Effect of fiber surface treatment on the fiber-matrix bond strength of natural fiber reinforced composites. Composites B 30:309-320

Wang X, Ren H, Zhang B, Fei B, Burgert I (2011) Cell wall structure and formation of maturing fibres of moso bamboo (Phyllostachys pubescens) increase buckling resistance. J R Soc Interface. https://doi.org/10.1098/rsif.2011.0462

Yuan XW, Jayaraman K, Bhattacharyya D (2007) Mechanical performance of plasma-treated natural fiber-polypropylene composites. In: Fakirov S, Bhattacharyya D (eds) Handbook of engineering biopolymers - homopolymers, blends and composites. Carl Hanser Verlag, München, pp 379-415

Publisher's Note Springer Nature remains neutral with regard to jurisdictional claims in published maps and institutional affiliations. 